ص ص[MT-1)

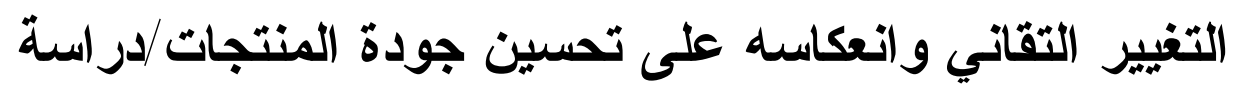

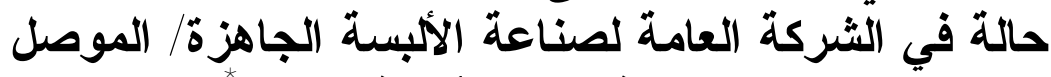

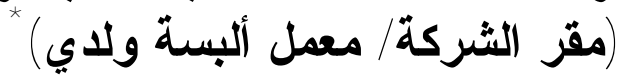

عبد العزيز بشار حسيب زكريا

a_m24441@yahoo.com

$$
\begin{aligned}
& \text { الدكتور محفوظ حمدون الصواف } \\
& \text { أستاذ - قسم إدارة الأعمال } \\
& \text { كلية الإدارة والاقتصاد -جامعة الموصل }
\end{aligned}
$$

Prof_mm@yahoo.com

المستخلص

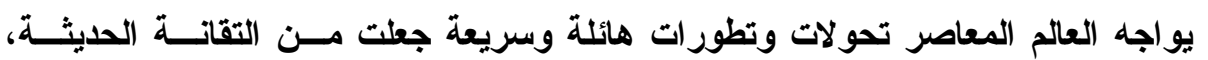

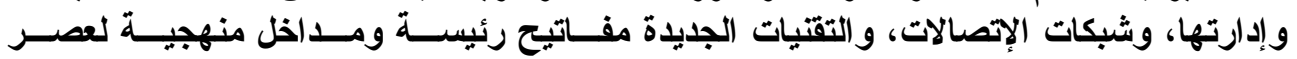

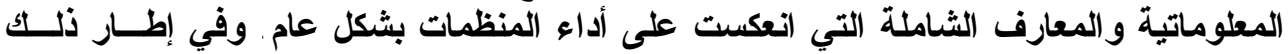

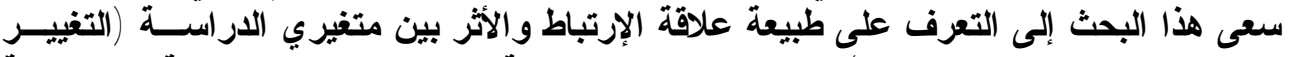

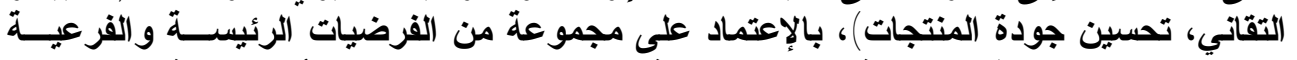

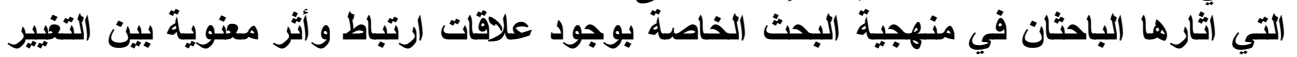

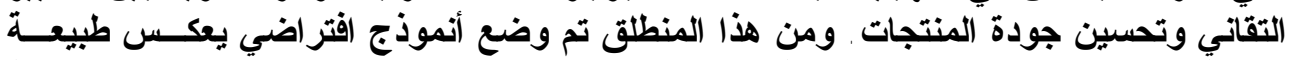

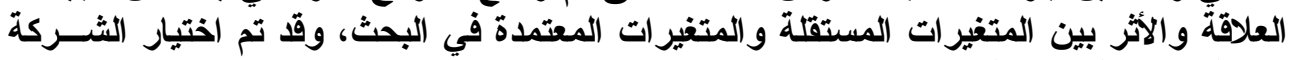

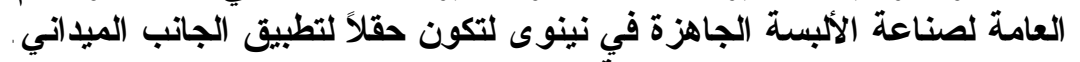

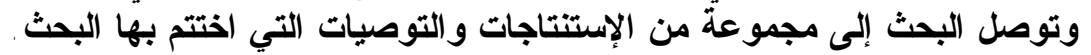

التغييز التقاني، جودة المنتجات، التحسين المستمر.

الكلمات المفتاحية:

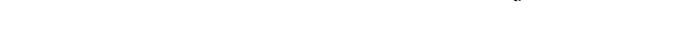

* بحث مستل من رسالة الماجستير في الإدارة الصناعية و الموسومة " التغيير التقاني و انعكاسه على تحسـينين

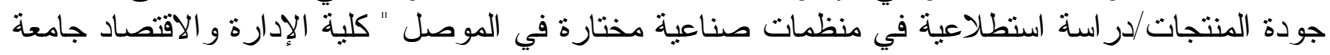

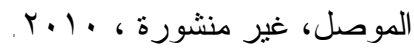




\title{
Technical Change and its Reflections on Products Quality Improvement A Case Study in General Company for the Ready Garments Industry
}

\author{
Mahfodh H. Al-Sawaf (PhD) \\ Professor \\ Department of Business Administration \\ University of Mosul
}

\author{
AbdulAziz B. Zakaria \\ Researcher \\ Department of Business Administration \\ University of Mosul
}

\begin{abstract}
The modern world has faced rapid changes that made the modern technology, management, network communications and new techniques the key systemic tools to the information and comprehensive knowledge era. These may be reflected in the performance of organizations in general. On this basis, this research aimed to know the nature of relation of correlation and the effect of the two variables of the study (technical variables, quality improvement of products). This can be done via the dependence of a group of major and minor hypotheses provoked by the researchers in research methodology, specially that there is a sort of correlation and effect whatsoever between technical variables and quality improvement of products. A model of hypothesis has been subjected to the nature of relation and effect of depended variables and independed in the study. General company for ready garments in Nineva has been selected to be the field of application.
\end{abstract}

\section{Key words:}

technology change, products quality, continuous improvement.

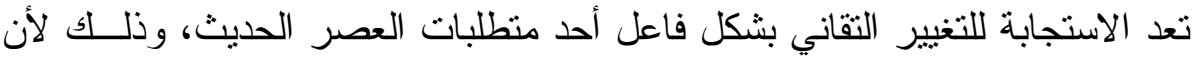

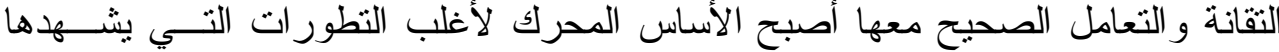

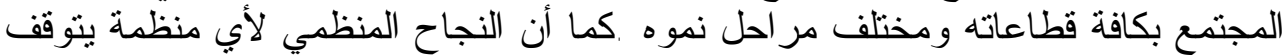

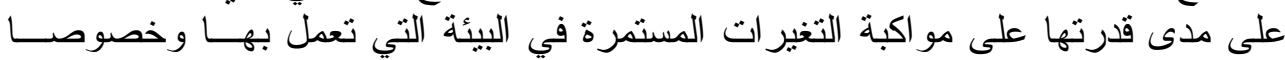

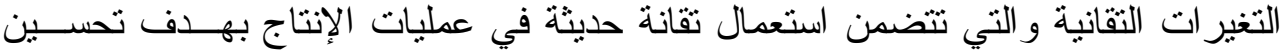

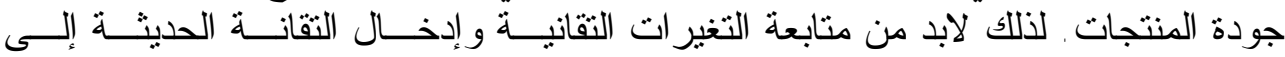
المنظمات بهدف النهوض بجودة منتجاتها من أجل التفوق على المنافين و الحصول على حصة سوقية أكبر .

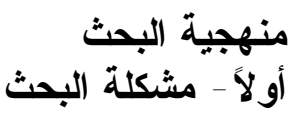

تعد التقانة أحد القدر ات الرئيسة للمنظمات الصناعية إذا ما أرادت البقاء في السوق

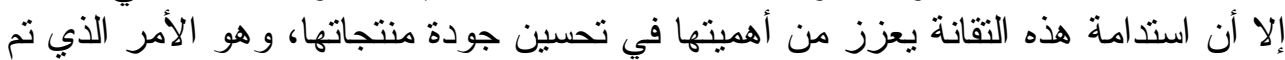

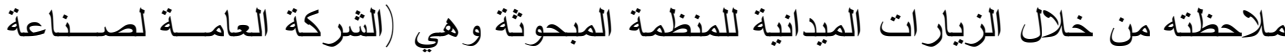

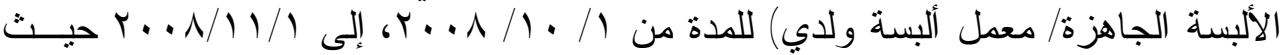

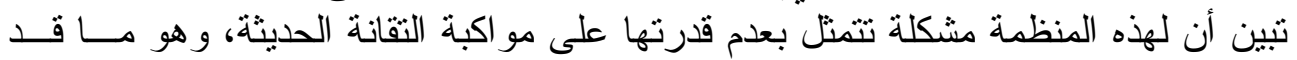
ينعكس سلباً على تحسين جودة منتجاتها. 
الصو اف وزكريا[119]

لكي تتمكن المنظمة من البقاء الذي يمثل أحد أهدافها علبها مو اكبة التطور ات التهات التهي

أهمية البحث

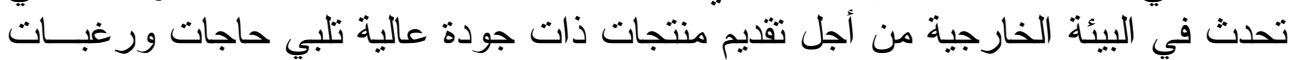

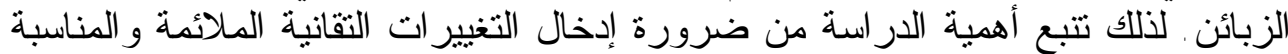

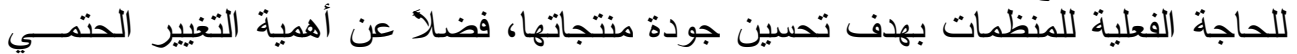

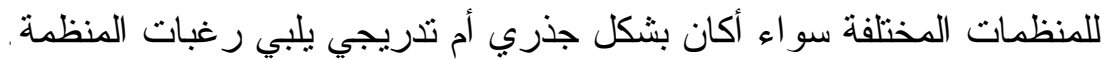

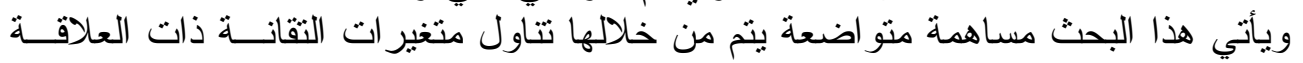
ودرجة تأثثر ها في جودة المنتجات .

$$
\text { تو افقاً مع تساؤلات البحث يسعى البحث إلى تحقيق الأهداف الآتية: }
$$

أهداف البحث

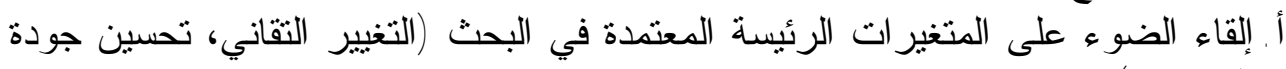

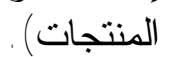

ب . الكثف عن و اقع التغيير التقاني في المنظمة عينة البحث. ت . الوقوف على و اقع تحسين جودة المنتجات في المنظمة عينة البحث . ث. اختبار طبيعة علاقة الارتباط و الأثر بين التغيير التقاني وتحسين جودة المنية المنتجات .

$$
\text { أنموذج البحث }
$$

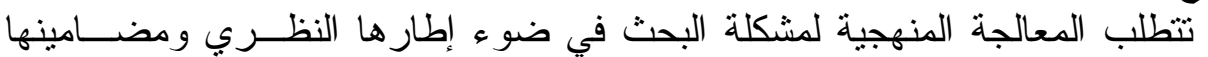

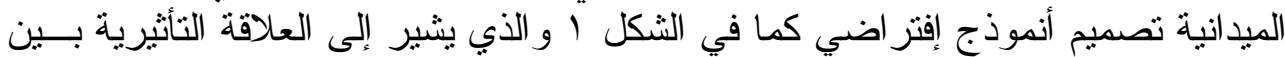
التغيير التقاني وتحسين جودة المنتجات، ويتضمن الأنموذج متغيرين رئيسين يتمنل الأول في (التغيير التثاني)، إذ يعد متغير آ مستقلا، بينما يتمثل المتغير الرئيس الثناني في (تحسين جودة المنتجات)، بوصفه متغير آ معتمداً.

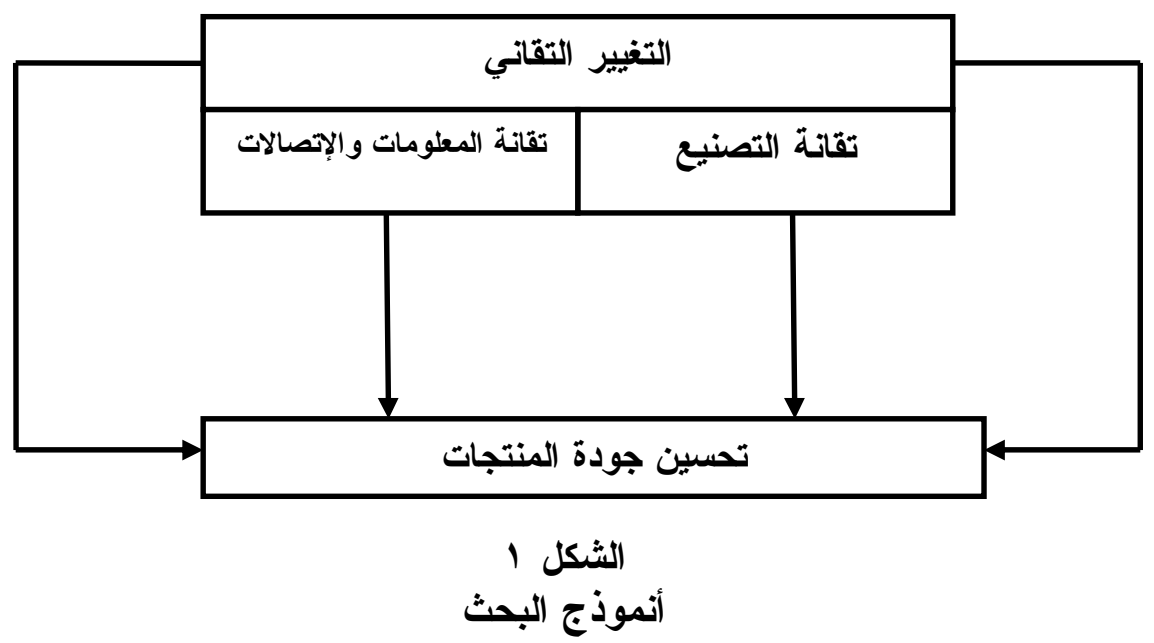

المصدر: الثكل من إعداد الباحثين. 
للإجابة عن تساؤلات مشكلة البحث وصو لا إلى تحقيق أهدافه حسدت الفرضــيات

$$
\text { فرضيات البحث }
$$

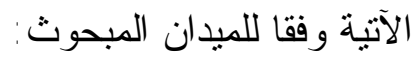

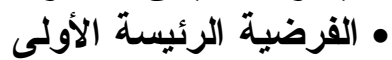

هناك علاقة ارتباط معنوية بين التغيير النقاني وتحسين جودة المنتجات .

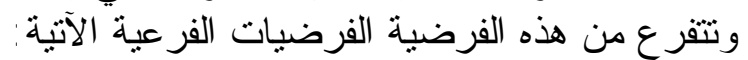

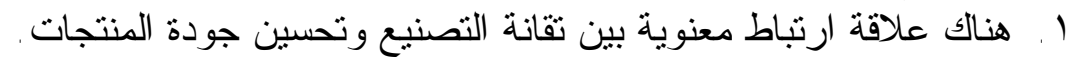

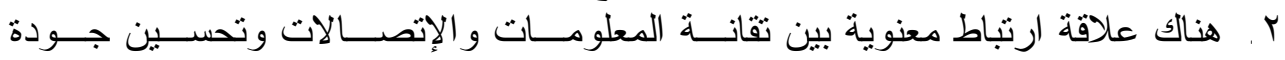

• (الفرضية الرئيسة الثانية

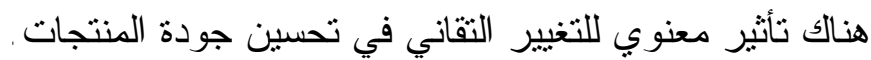

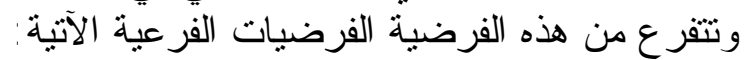

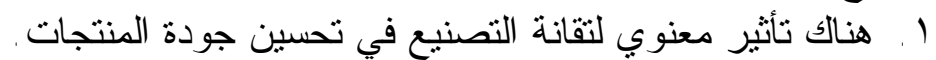
r. ـ هناك تأثثر معنوي لتنقانة المعلومات و الإتصالات في تحسين جودة المنتجات

$$
\text { حدود البحث }
$$

1 ـ الحدود الزمانية: انحصرت حدود البحث في الددة الزمنيــة مــن ب/9/9 . ب إلــى

$$
\text { . r. . 9/9/1 }
$$

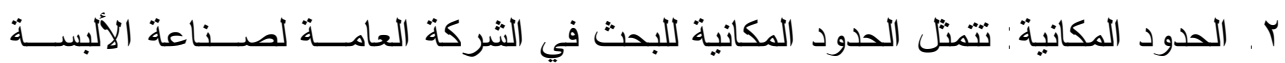
الجاهزة (مقر الثركة/ معمل ألبسة ولدي).

\section{أساليب جمع البيانات}

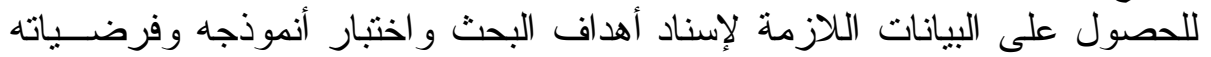

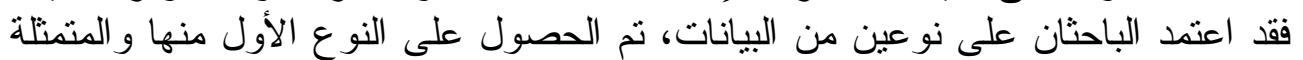

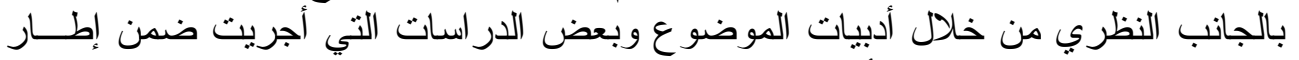

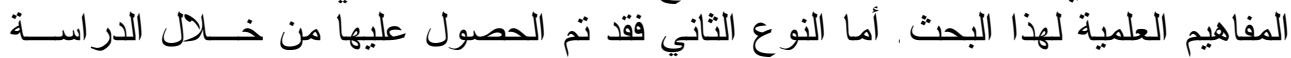

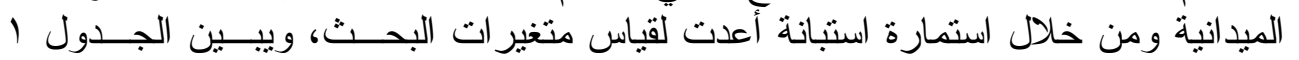

\begin{tabular}{|c|c|c|c|c|c|}
\hline المصدر & عدد الأسئلة & المتغيرات الفرعية & الفقرات & الرئتيرات & 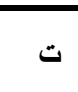 \\
\hline - عبنزة الدراسة الميدانية للمنظمسات & 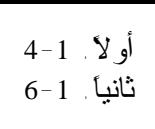 & بالاستمارة & - & معلومات عامة & أولاً \\
\hline 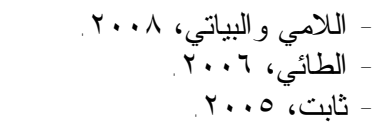 & $\mathrm{X}_{10}-\mathrm{X}_{1}$ & تقانة التصنيع & -1 & التغيير الثقاني & ثانياً \\
\hline
\end{tabular}

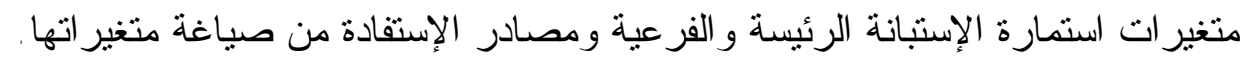

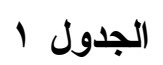

متغيرات استمارة الإستبانة 


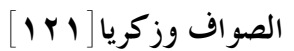

\begin{tabular}{|c|c|c|c|c|c|}
\hline المصدر & عدد الأسئلة & المتغيرات الفرعية & تسلسل & المتئيرة ات & $ت$ \\
\hline 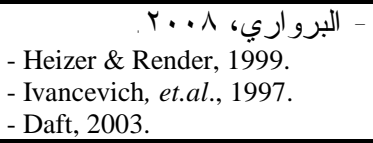 & $\mathrm{X}_{24}-\mathrm{X}_{11}$ & تو الإتصـــالات المعلومـــــات & 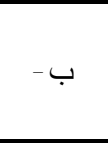 & & \\
\hline 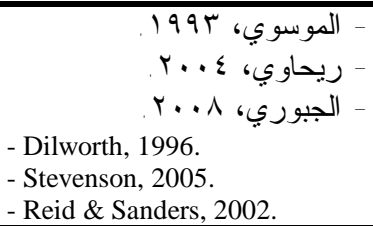 & $\mathrm{X}_{38}-\mathrm{X}_{25}$ & - & - & تحسين جودة & ثالثاً \\
\hline
\end{tabular}

المصدر: الجدول من إعداد الباحثين.

\section{وصف الميدان المبحوث والية توزيع استمارة الاستبانة}

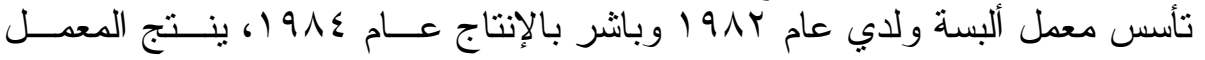

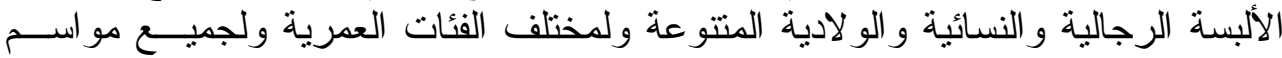

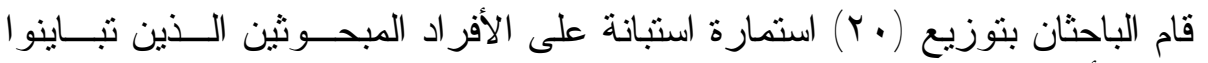

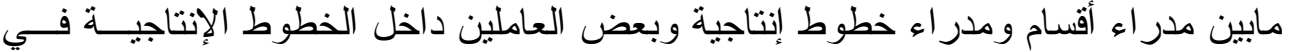

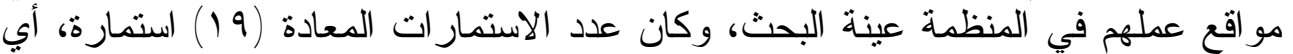
إن نسبة الإستجابة بلغت (90\%)

$$
\text { أولاًَ - مفهوم التقانيير التغيير التقاني وأهميته }
$$

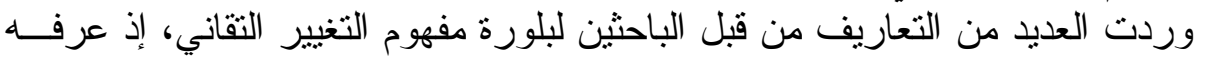

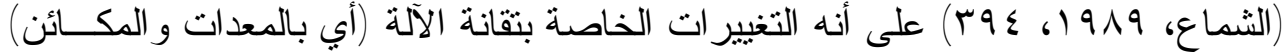

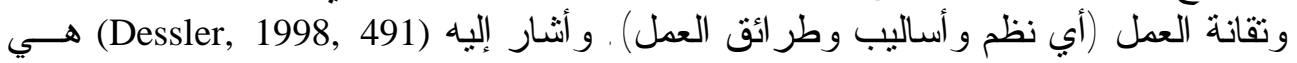

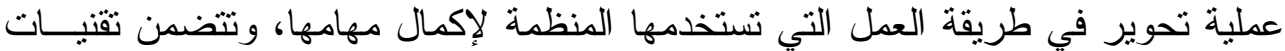

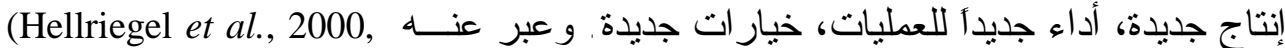

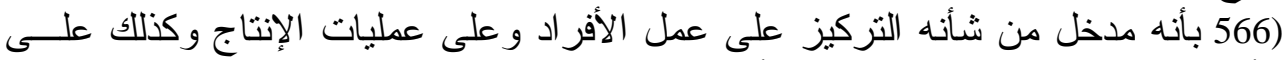

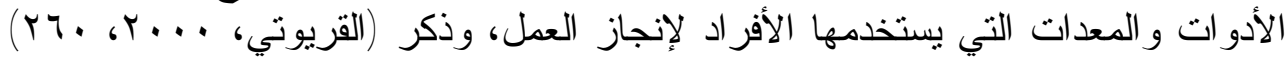

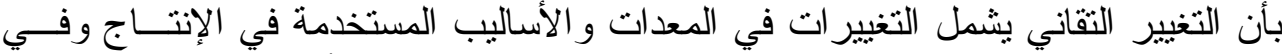

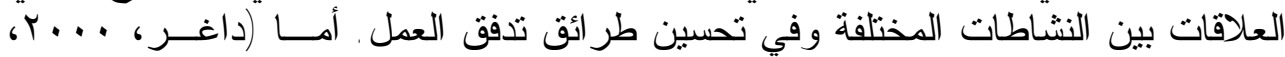

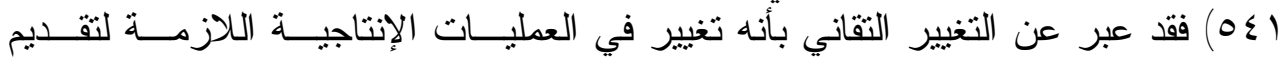

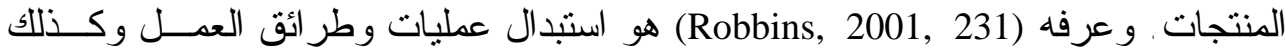
المعدات المستخدمة في العمل، ور أى (Griffin, 2002, 394) أنهاته عملية إدخال ثقانة حديثـة

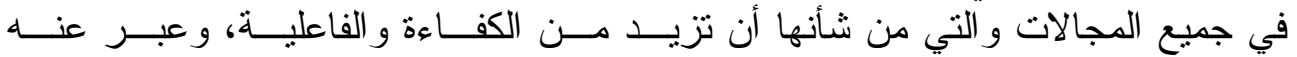

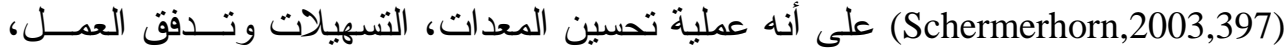

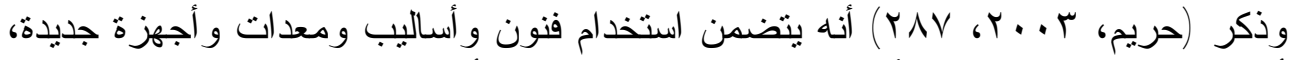

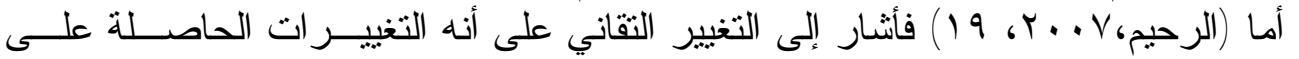


أساليب العمل و إدخال المكننة في المنظمة وبالإجر اءات المتعلقة بتحقيق كفاءة أعلى فـي

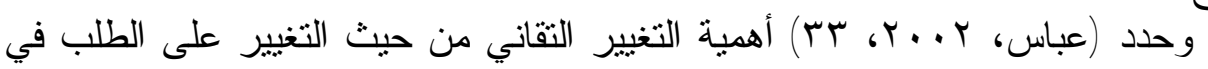

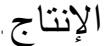

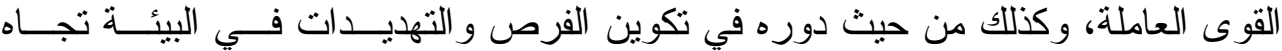

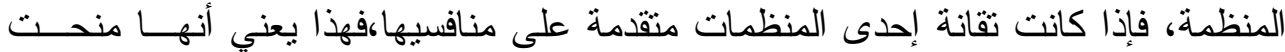

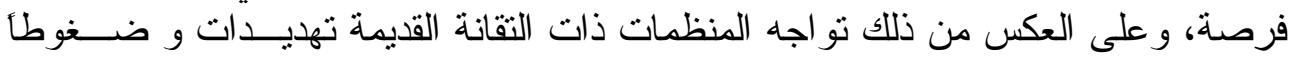

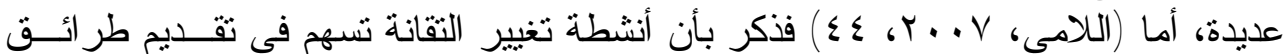

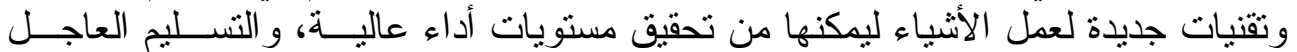
للمنتجات، وتقديم خدمات أفضل للزباء لائن.

إن كلمة نقانة هي تعريب لكلمة (Technology) و التي هي مشتقة من الكلمة اليونانية

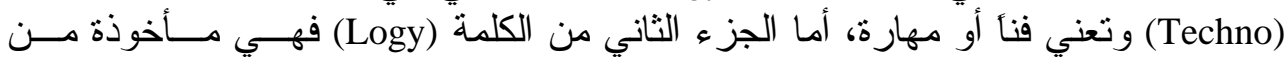

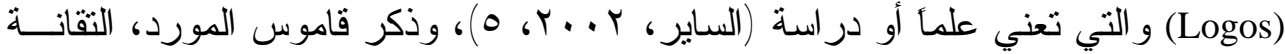

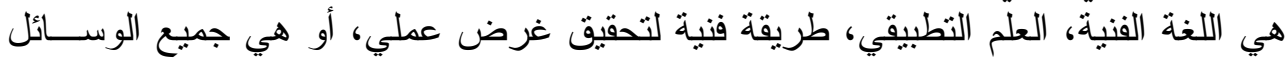

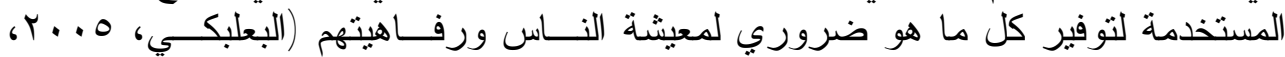
$.190 \leq$

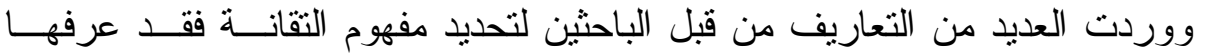
(Hodge and Authony, 1991,395)

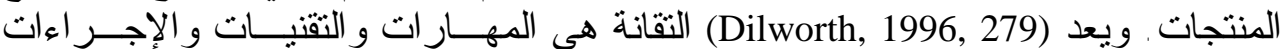
و المعدات و الأنظمة التي تنتخدم لأداء العمل . و أكد (Dlack et al., 1998, 267) بأن التقانة

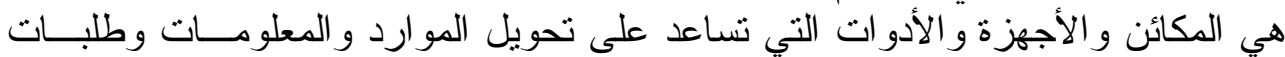
الزبائن من أجل إضافة قيمة لها و إنجاز الهدف الاستر اتيجي للعملية. أما Krajewski, and

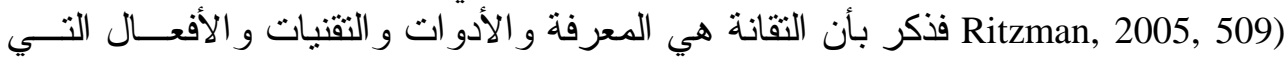

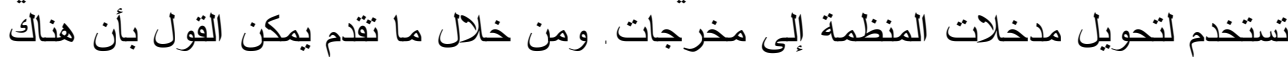

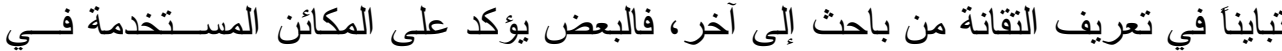

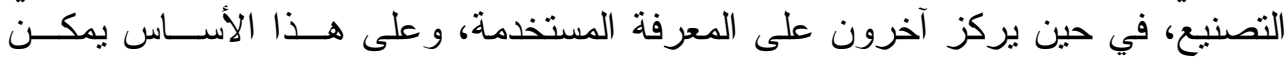

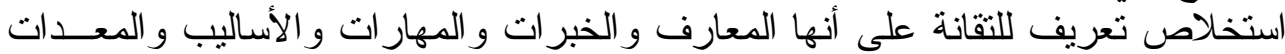

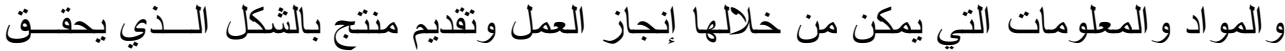

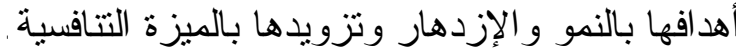

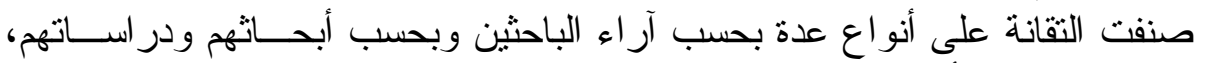
و الجدول الآتي يوضح أصناف التقانة.

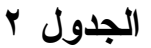

تصنيف التقانة لاى عدد من الباحثين

\begin{tabular}{|c|c|c|c|}
\hline تصنيف التقانة & الباحث & السنة & ت \\
\hline - تقانة الخدمة. & Chase and Aquilano & 1995 & .1 \\
\hline - التقانة الآلية (المؤتمتة) . & Wright and Noe & 1996 & .2 \\
\hline
\end{tabular}




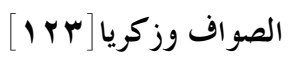

\begin{tabular}{|c|c|c|c|}
\hline تصنيف التقانة & الباحث & السنة & ت \\
\hline 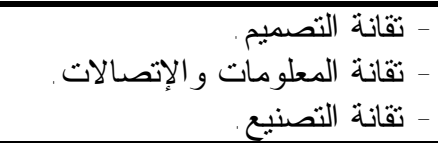 & Russell and Taylor & 1998 & .3 \\
\hline - ثقانة الإنتاج (التصيم التصنيع) . & Heizer and Render & 1999 & 4 \\
\hline - نقانة العملية المعلومات و الإتصالات . & Robbins and Decenzo & 2001 & .5 \\
\hline - تقانة التصنيع. & Griffin & 2002 & .6 \\
\hline - التقانة الرقدمة. & Daft & 2003 & .7 \\
\hline - تقانة - نقانة التصنيع. & Davis, et. al. & 2003 & .8 \\
\hline 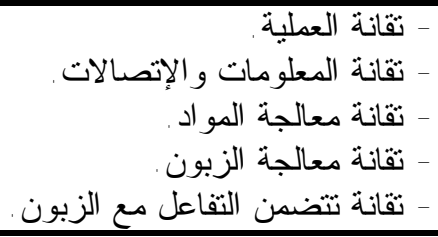 & Slack, et. al. & 2004 & .9 \\
\hline - نقانة العملية المنتج. & Krajewski and Ritzman & 2005 & .10 \\
\hline - نقانة الأجهزة و المعدات. & Evans and Collier & 2007 & .11 \\
\hline
\end{tabular}

المصدر: الجدول من إعداد الباحثين بالاعتماد على آر اء بعض الباحثين.

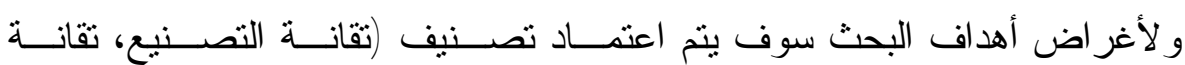

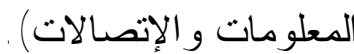

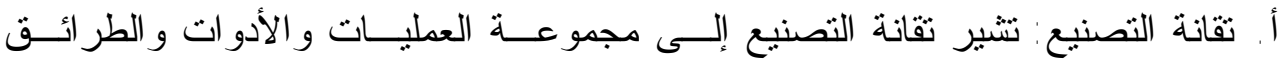

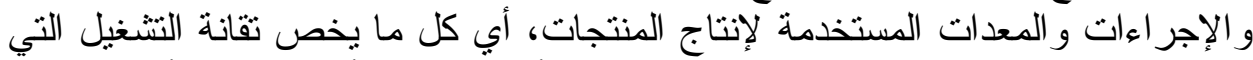

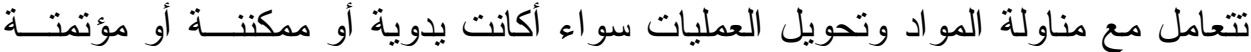

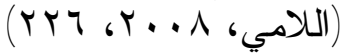

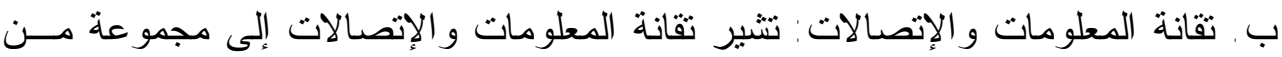

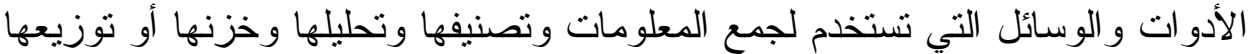
. ((Slack et al., 2004, 254

تحسين جودة المنتجات

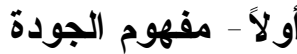

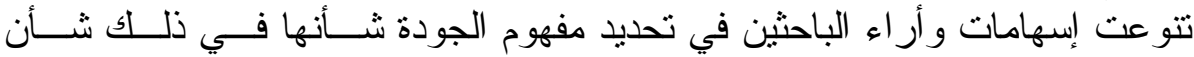
المفاهيم الإدارية الأخرى، وتمثل الجودة مصطلحا له استعمالات عديدة، وبهدف التوصـلـل فئل 


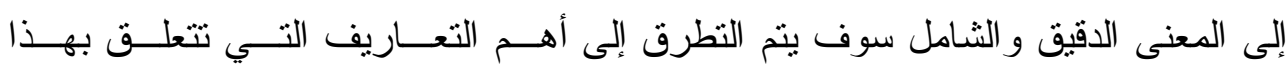

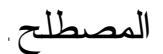

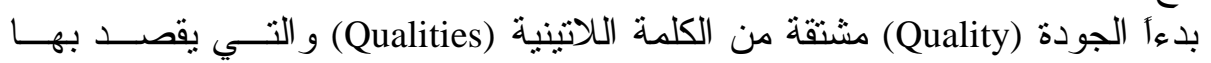

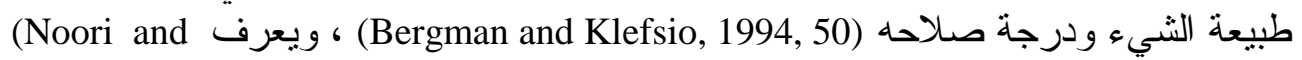
Radford, 1995, 158)

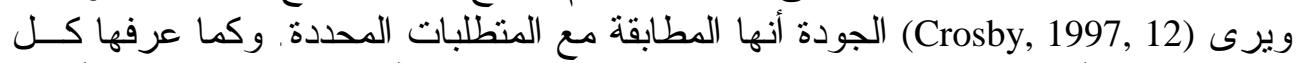

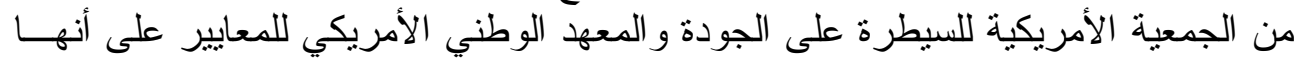

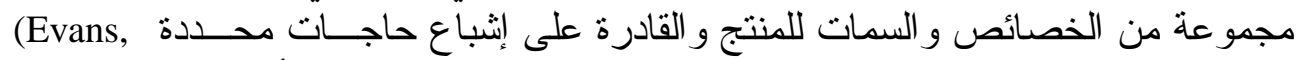

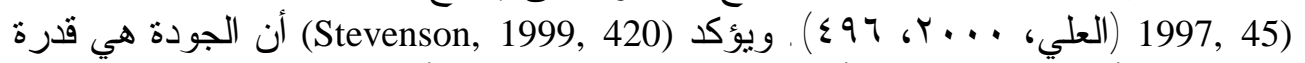

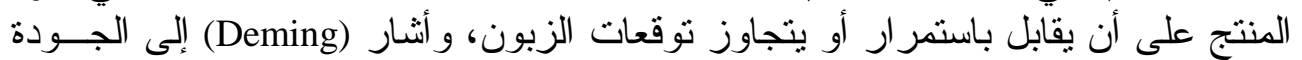

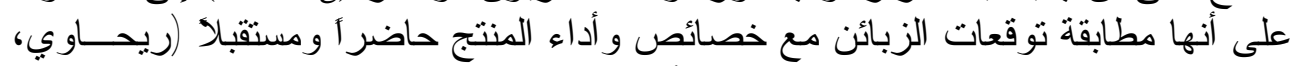

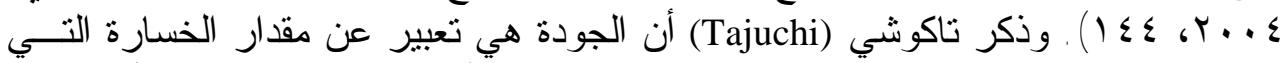

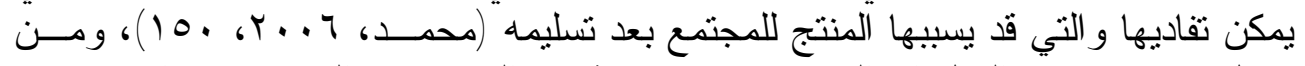

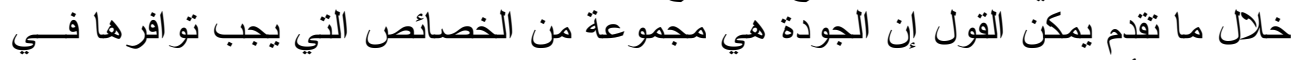
المنتج من أجل مقابلة منطلبات الزبون وتحقيق رئ رضاه و وإسعاده.

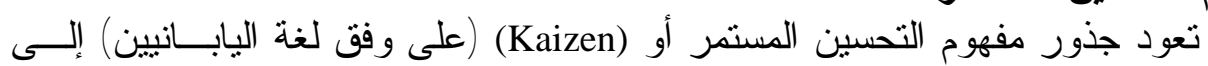

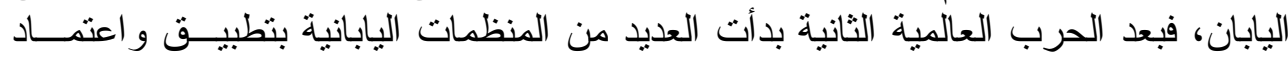

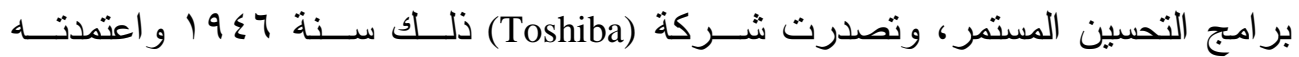
سنة . 190 1901 وشركة (Moyotasushita Electric)

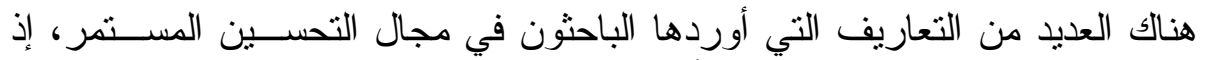

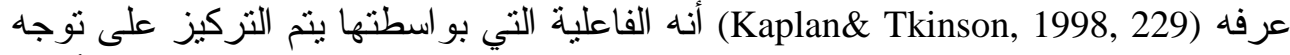

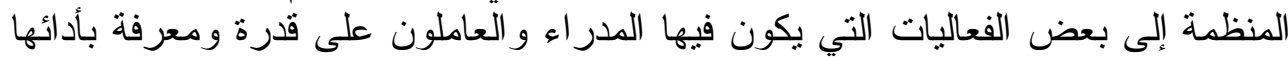

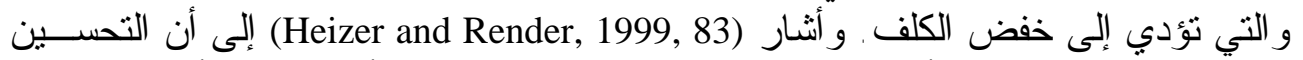

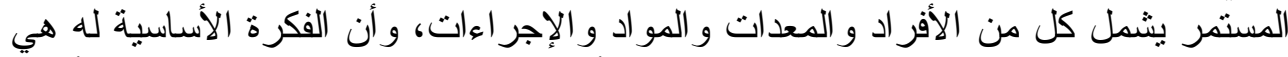

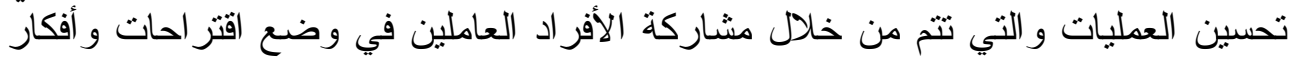

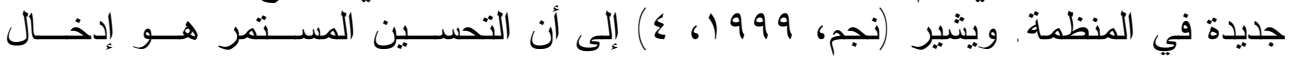

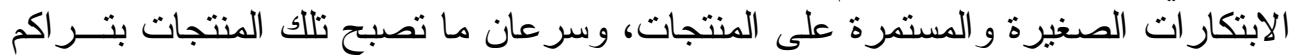

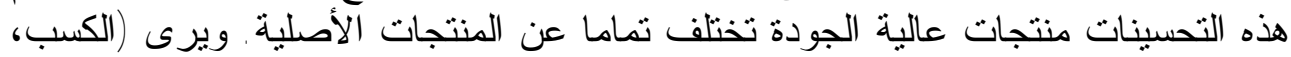

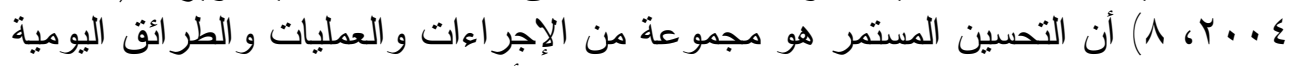

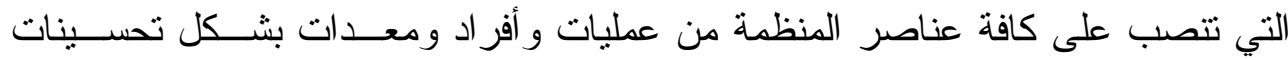

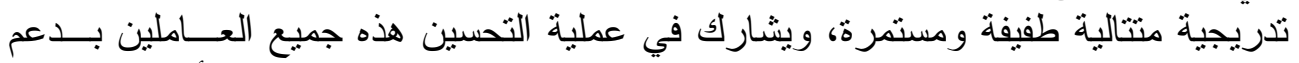

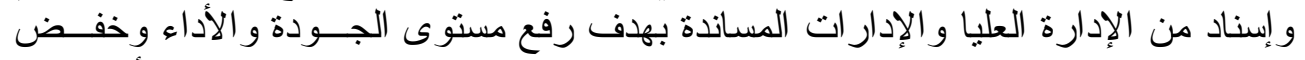

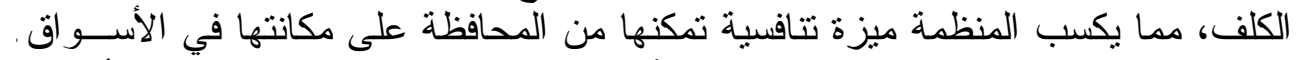

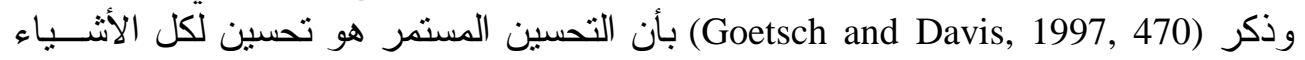

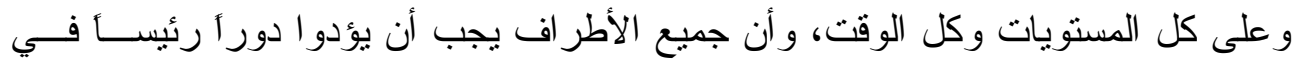

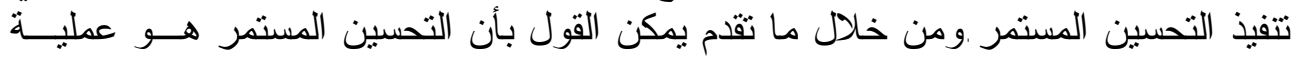




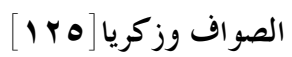

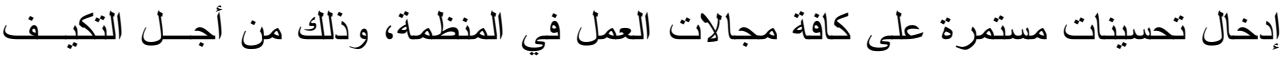
الدائم مع المتغيرات التي تحدث في بيئتي المنظمة الداخلية والخارجية.

$$
\text { - الجاتب الميداني }
$$

أولاً - العلاقة بين متغيرات التغيير التقاني وتحسين جودة المنتجات على مستوى الثركة

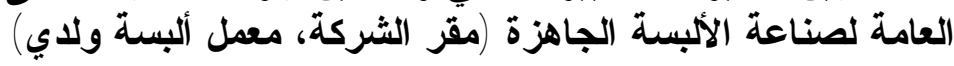

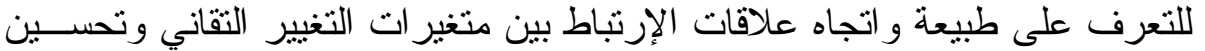

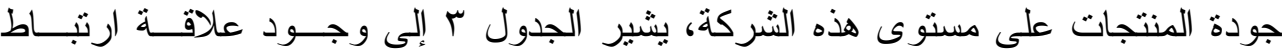

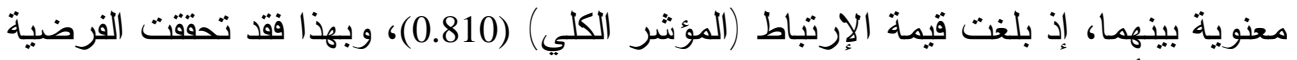

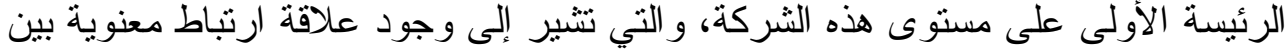
التغيير النقاني وتحسين جودة المنتجات.

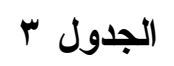

\begin{tabular}{|c|c|}
\hline تحسين جودة المنتجات & المتغير المستقل \\
\hline $0.701^{*}$ & تقانة التصنيع \\
\hline $0.790 *$ & تقانة المعلومات و الاتصالات \\
\hline $0.810^{*}$ & المؤشر الكلى \\
\hline
\end{tabular}

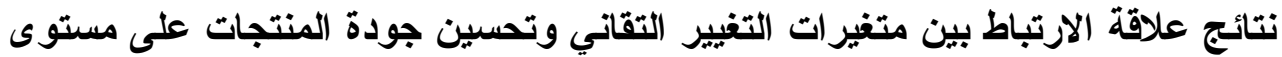

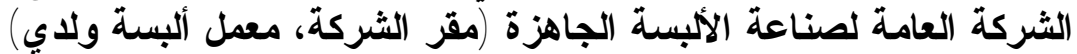

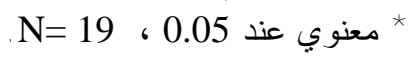

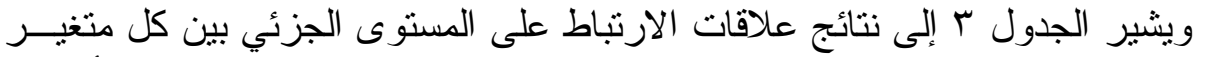

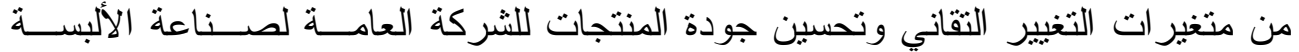

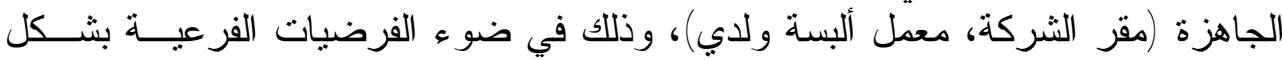

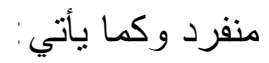
أ. العلاقة بين تقاتة التصنيع وتحسين جودة المنتجات

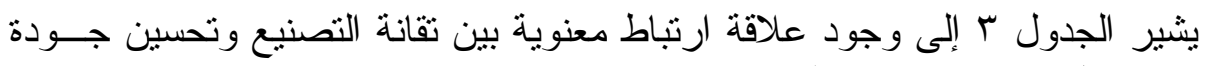
المنتجات، إذ بلغت درجة الارتباط (0.701)، عند مسنوى معنوي (0.05). ب. العلاقة بين تقاتة المعلومات والإنصالات وتحسين جودة المنتجات

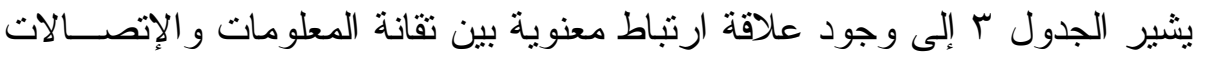
وتحسين جودة المنتجات، إذ بلغت درجة الإرتباط (0.790)، عند مستوى معنوي (0.05). 
ثانياً - تأثير التغيير التقاني في تحسين جودة المنتجات على مســـتوى الثـــركة العامـــة لصناعة الألبسة الجاهزة (مقر الشركة، معمل ألبسة ولاندي)

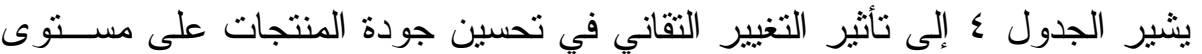

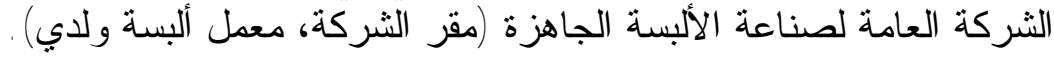

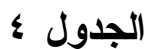

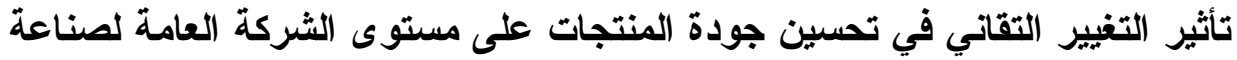

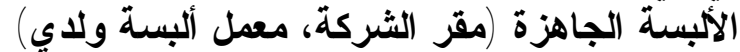

\begin{tabular}{|c|c|c|c|c|c|}
\hline \multicolumn{2}{|c|}{$\mathbf{F}$} & \multirow{2}{*}{$\mathbf{R}^{2}$} & \multicolumn{2}{|c|}{ التغيير التقاني } & \multirow[t]{2}{*}{ المتغير المستقل } \\
\hline الجدولية & المحسوبة & & B1 & B0 & \\
\hline 4.451 & $27.347 *$ & 0.617 & $\begin{array}{c}0.651 \\
(5.229)^{*}\end{array}$ & 1.157 & تحسين جودة المنتجات \\
\hline
\end{tabular}

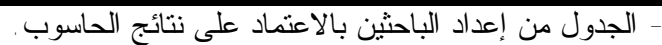

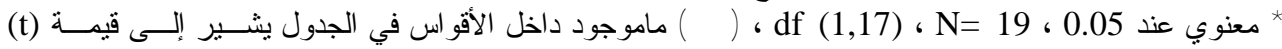

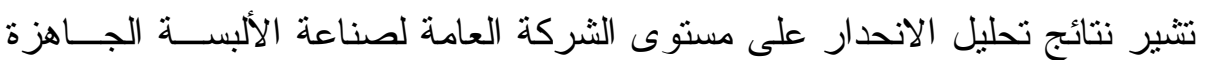

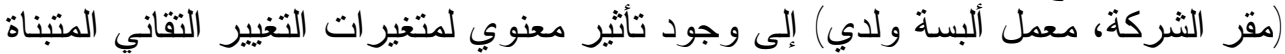

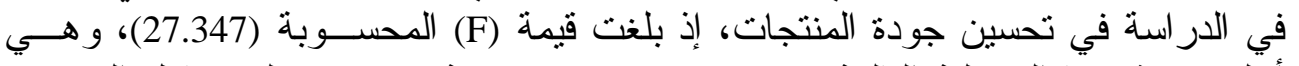

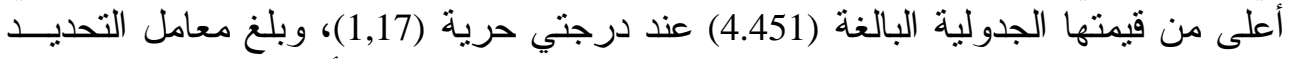

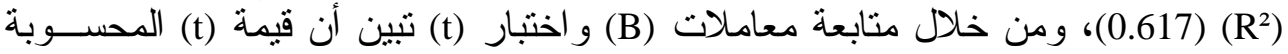

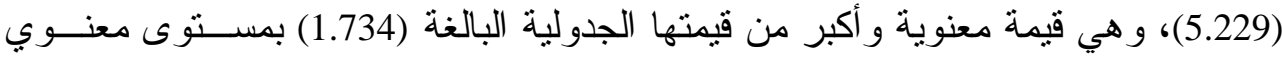

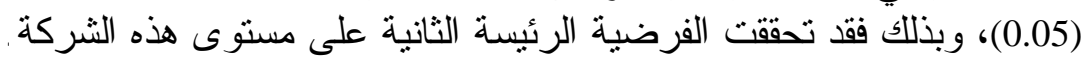

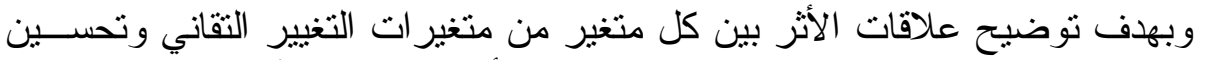

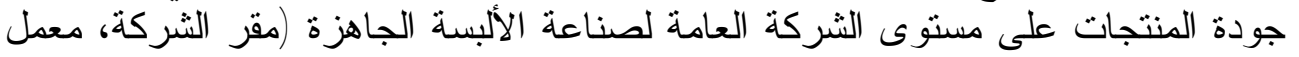

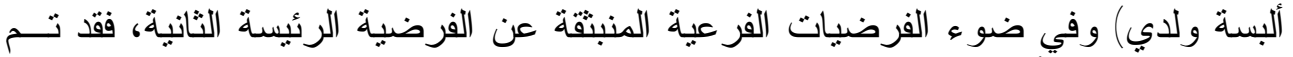

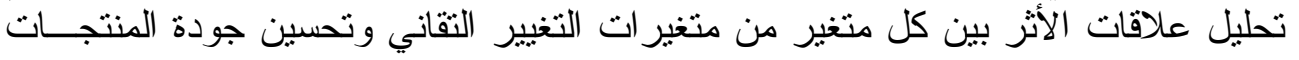

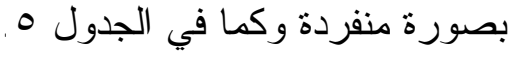

\section{الجدول}

تأثير كل متغير من متغيرات التغيير التقاني في تحسين جودة المنتجات على مستوى ألتول الثركة العامة لصناعة الألبسة الجاهزة (مقر الشركة، معمل ألبسة ولاتئي

\begin{tabular}{|c|c|c|c|c|c|c|}
\hline \multicolumn{2}{|c|}{$\mathbf{F}$} & \multirow{2}{*}{$\mathbf{R}^{2}$} & المعلومات & تقانة & \multirow{2}{*}{ B0 } & \multirow{2}{*}{ المتغير المعتمد المتغير المستقل } \\
\hline الجدولية & المحسوبة & & B2 & B1 & & \\
\hline 3.633 & $15.904 *$ & 0.665 & $\begin{array}{c}0.474 \\
(2.886) *\end{array}$ & $\begin{array}{c}0.265 \\
(1.400)\end{array}$ & 1.084 & تحسين جودة المنتجات \\
\hline
\end{tabular}




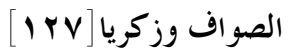

وتتثير نتائج تحليل الانحدار إلى مدى تأثئر كل متغير من متغير ات التغيير الثقـــي في تحسين جودة المنتجات وكما في الآتي:

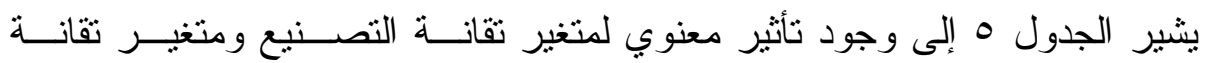

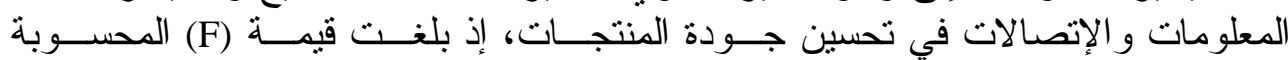

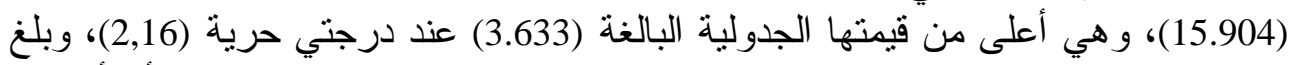

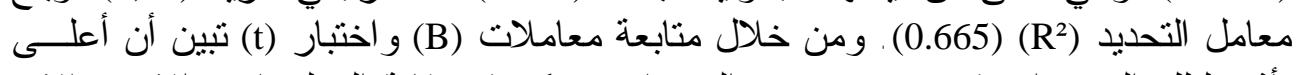

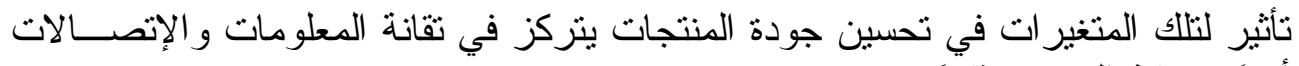
أو لأ، وتقانة التصنيع ثانياً.

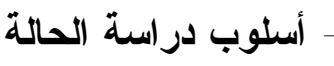

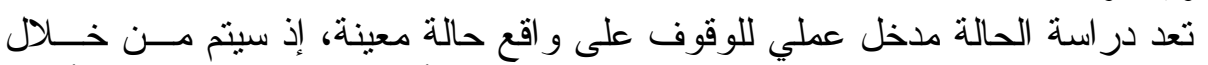

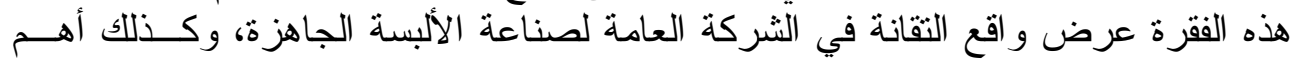

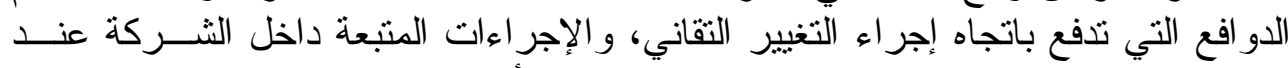

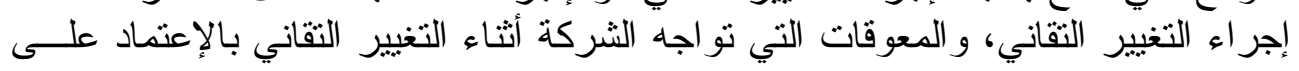
المعايشة الميدانية وألمقابلات الني إجريت داخل معمل البسة ولدي ومقر الثركة.

أولاً - واقع التغيير التقاني داخل الثركة العامة لصناعة الألبسة الجاهزة

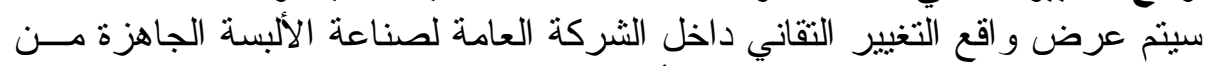

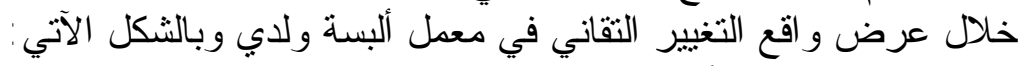

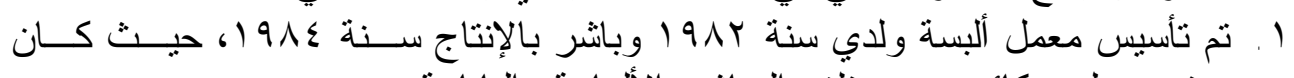

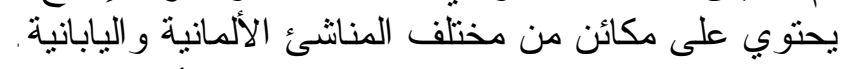

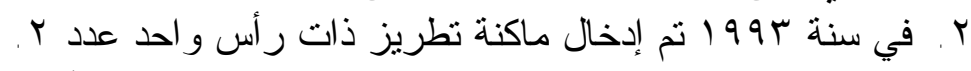

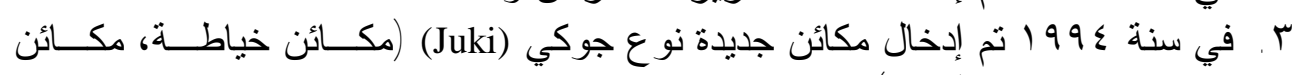

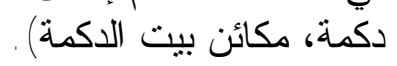

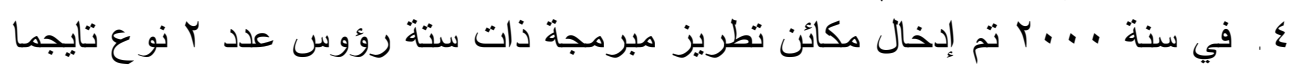
.(Taegma)

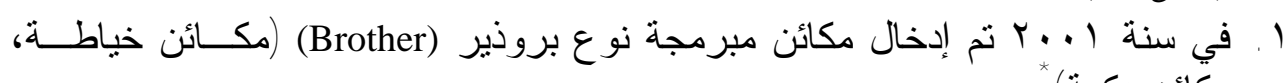

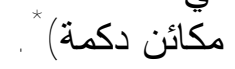

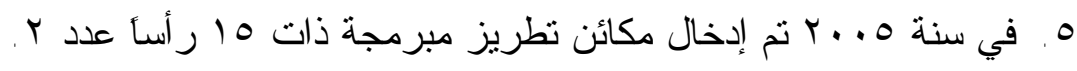

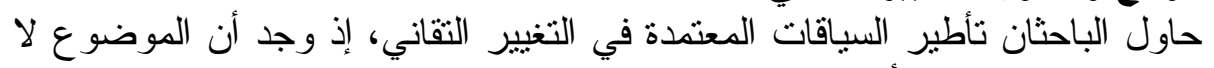

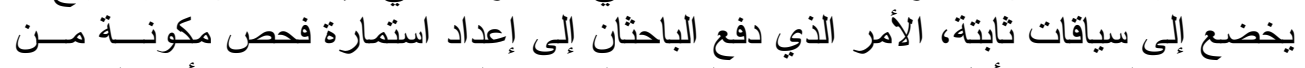

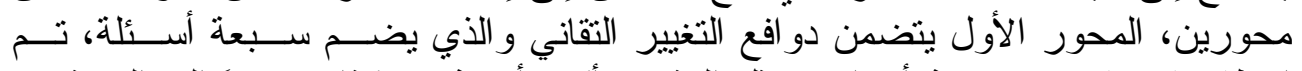

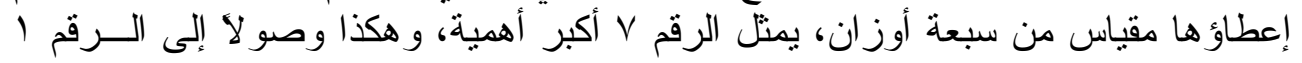




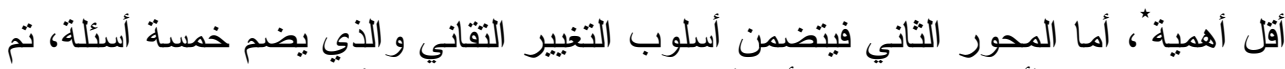

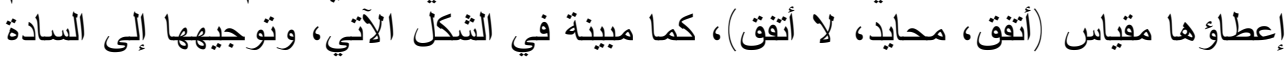

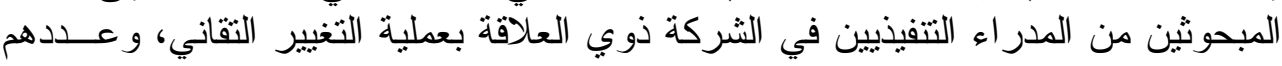
عثرة تم ترنيهـ من

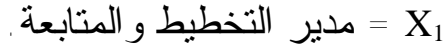
مدير البحث و التطوير = X X مدير القسم التجاري. X X مدير المالية.

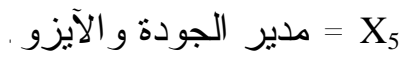
مدير شعبة الدر اسات . X X مدير القسم الفني. = X $X_{8}$ مدير معمل ولدي. X X Sدير معمل النسيج. X X X

\begin{tabular}{|c|c|c|c|c|c|c|c|c|}
\hline & & & & & & هصر & \multicolumn{2}{|c|}{ 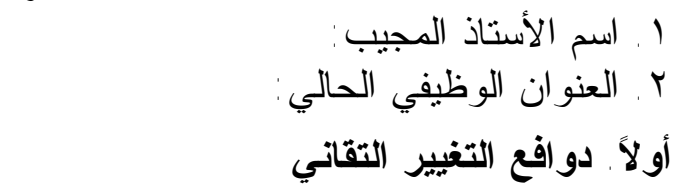 } \\
\hline \multirow[t]{8}{*}{1} & 2 & 3 & 4 & 5 & 6 & 7 & | & 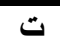 \\
\hline & & & & & & & زيادة الطلب على المنتجات & .1 \\
\hline & & & & & & & و توفر التخصيص المالي من قبل وزارة الصــــاعة & .2 \\
\hline & & & & & & & السعي لتحسين جودة المنتجات & .3 \\
\hline & & & & & & & السعي لتخفيض تكلفة المنتجات & .4 \\
\hline & & & & & & & زيادة حدة المنافسة & .5 \\
\hline & & & & & & & السعي للحصول على هامش ربح جيذ & .6 \\
\hline & & & & & & & تقادم المكائن و المعدات & .7 \\
\hline \multicolumn{9}{|c|}{ ثانياً. أسلوب التغيير التقاني } \\
\hline & & 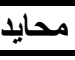 & & اتفق & & & | & $ت$ \\
\hline & & & & & & & يتت بأسلوب النقلة السريعة. & .1 \\
\hline & & & & & & & يتم بأسلوب التحسينات المستمرة البسيطة. & .2 \\
\hline & & & & & & 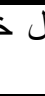 & سنوات التغيير التقاني خلال فترات زمنية معينة () & .3 \\
\hline & & & & & & & سنوات التغيير التقاني خلال فترات زمنية معينــة & .4 \\
\hline & & & & & & من & سنوات التغيير التقاني خلال فتز ات زمنية معينة (أ) & .5 \\
\hline
\end{tabular}




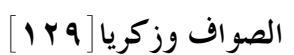

وكانت إجابات المدر اء المبحوثين كما مبينة في الجداول الآتية:

\begin{tabular}{|c|c|c|c|c|c|c|c|c|}
\hline \multicolumn{9}{|c|}{ ملخص يوضح النسب التي حصل عليها كل متغير من متغير ات دوافع التغيير التقاني } \\
\hline 1 & 2 & 3 & 4 & 5 & 6 & 7 & العبار ات / الأوزان & $ت$ \\
\hline$\% 10$ & $\% \underline{\underline{30}}$ & $\% 20$ & $\% 10$ & $\% 0$ & $\% 20$ & $\% 10$ & زيادة الطلب على المنتجات. & 1 \\
\hline$\% 0$ & $\% 0$ & $\% 0$ & $\% 0$ & $\% 0$ & $\% 10$ & $\% \underline{90}$ & 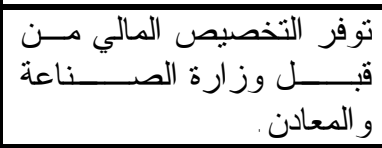 & 2 \\
\hline$\% 10$ & $\% 0$ & $\% 0$ & $\% 20$ & $\% 0$ & $\% \underline{70}$ & $\% 0$ & 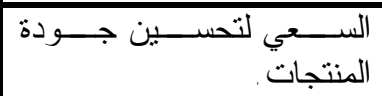 & 3 \\
\hline$\% 10$ & $\% 20$ & $\% 10$ & $\% 10$ & $\% \underline{50}$ & $\% 0$ & $\% 0$ & 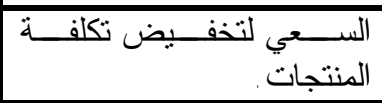 & 4 \\
\hline$\% 10$ & $\% 10$ & $\% 30$ & $\% \underline{\underline{40}}$ & $\% 10$ & $\% 0$ & $\% 0$ & زيادة حدة المنافسة. . & 5 \\
\hline$\% \underline{60}$ & $\% 20$ & $\% 0$ & $\% 10$ & $\% 10$ & $\% 0$ & $\% 0$ & ربح جيد. للحصول على هامش & 6 \\
\hline$\% 0$ & $\% 20$ & $\% \underline{40}$ & $\% 10$ & $\% 30$ & $\% 0$ & $\% 0$ & تقادم المكائن و المعدات. & 7 \\
\hline
\end{tabular}

\section{الجدول}

ملخص يوضح النسب التي حصل عليها كل متغير من متغيرات أسلوب التغيير التقاني

\begin{tabular}{|c|c|c|c|c|}
\hline ل الا اتقق & 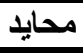 & اتفق & العبار ات / مستوى الاستجابة & $ت$ \\
\hline$\% 30$ & $\% 0$ & $\% 70$ & يحدث التغيير التقاني بأسلوب النقلة السريعة. & 1 \\
\hline$\% \underline{70}$ & $\% 0$ & $\% 30$ & البسيطةث التغيير التقاني بأسلوب التحســينات المســتمرة & 2 \\
\hline$\% \underline{90}$ & $\% 0$ & $\% 10$ & 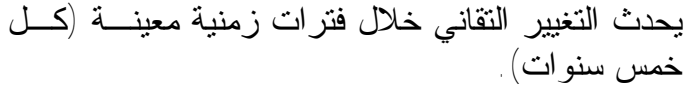 & 3 \\
\hline$\% \underline{100}$ & $\% 0$ & $\% 0$ & عشرث سنو التغيير التقاني خلال فتر ات زمنية معينــة (كـلـل & 4 \\
\hline$\% 10$ & $\% 0$ & $\% \underline{90}$ & من عند التغيير التقاني خلال فتر ات زمنية معينة (أكتــر & 5 \\
\hline
\end{tabular}

الجدول من إعداد الباحثين . ات.

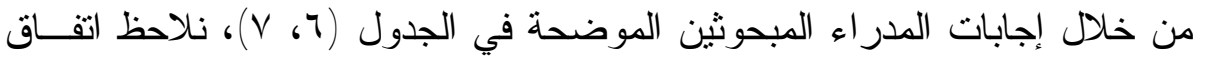

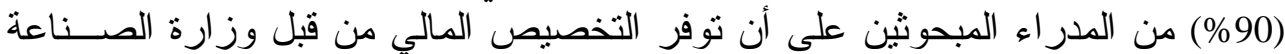

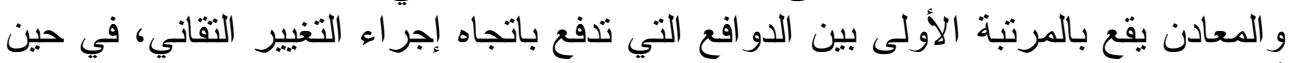

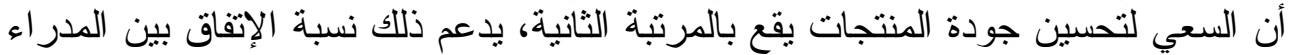

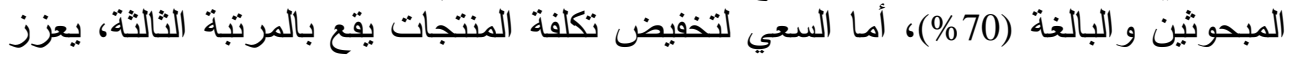

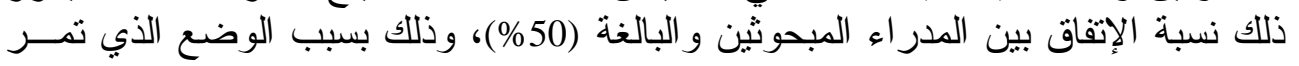

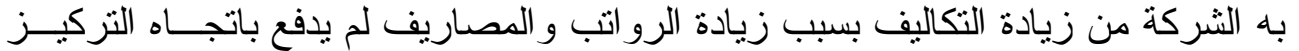

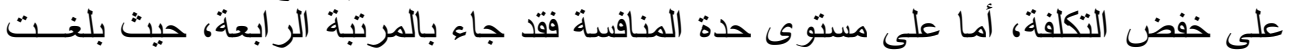




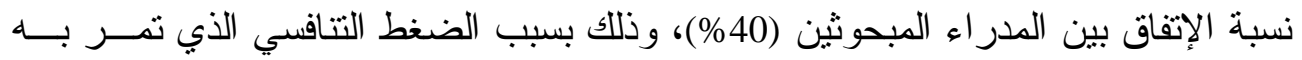

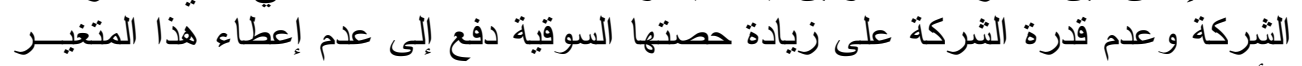

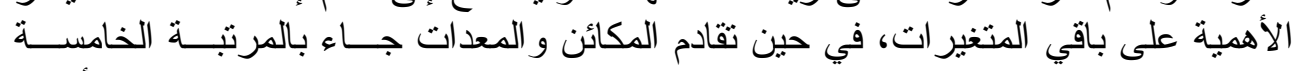

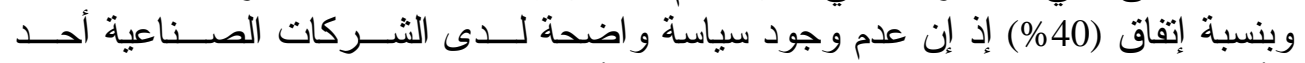

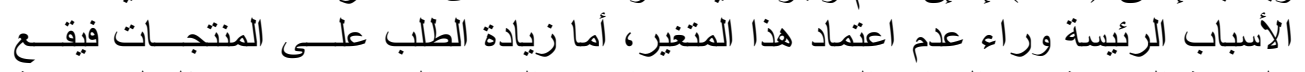

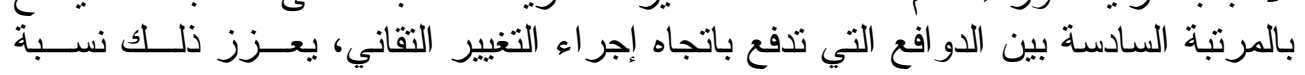

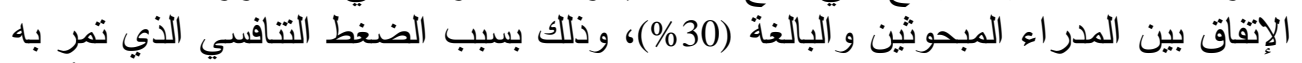

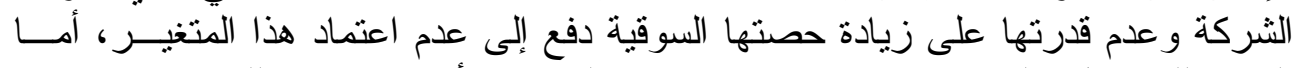

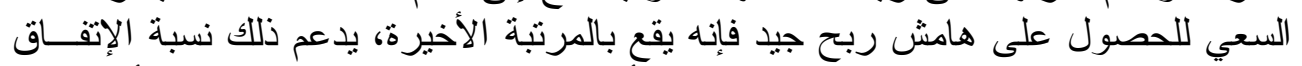

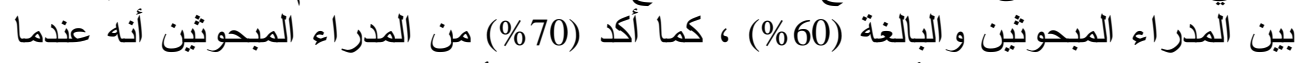

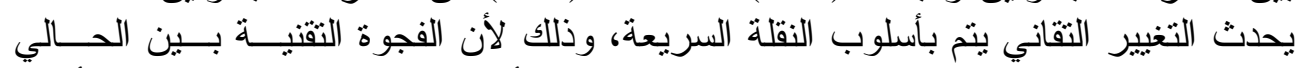

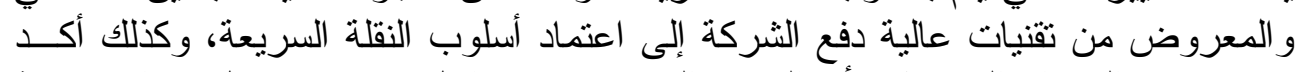

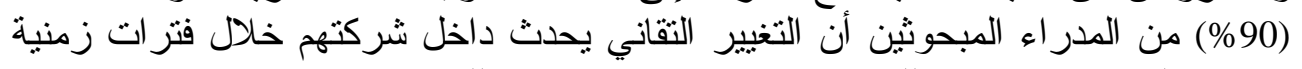

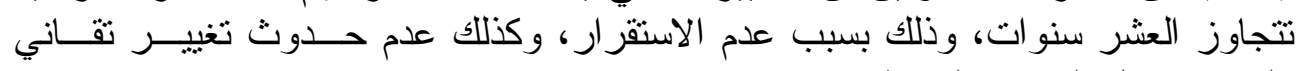
ملموس خلال الفنز ات السابقة .

ثالثاً - الإجراءات المتبعة داخل الثركة العامة لصناعة الألبسة الجاهزة (معــل ولــدي)

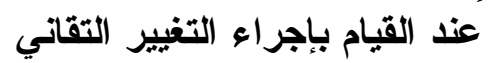

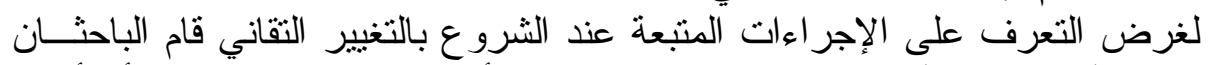

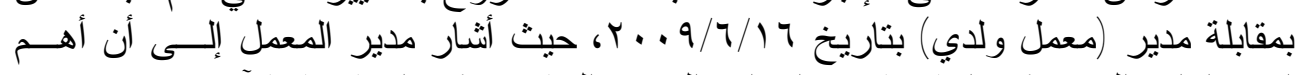

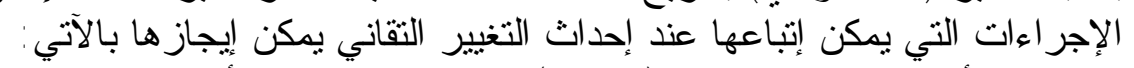

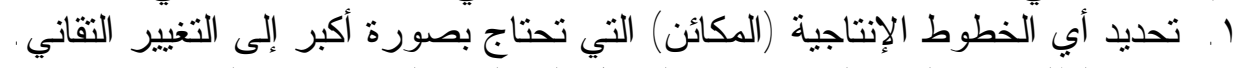

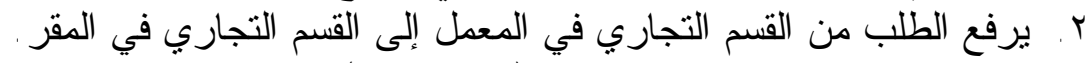

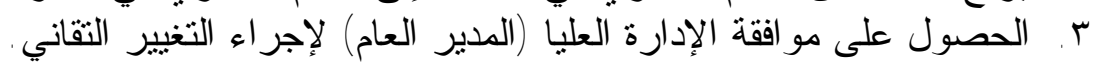

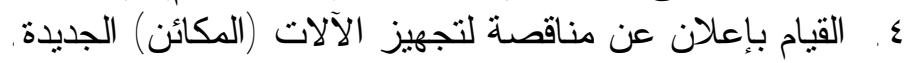

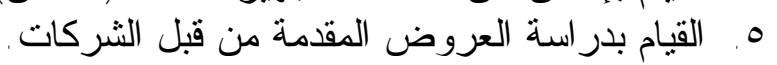
7. اختيار العرض المناسب لتجهيز الثركة بالآلات (الككائن) الجديدة.

رابعاً. أهم المعوقات التي تواجه عملية التغيير التقاني داخل الثـــركة العامــة لصـــاعة

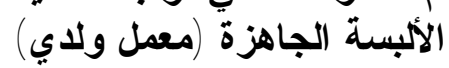

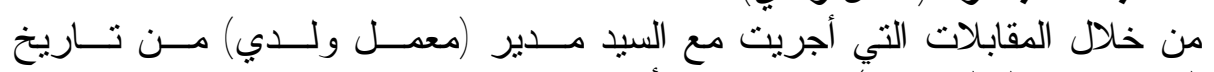

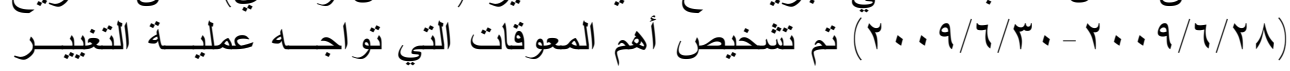
التقاني و التي بمكن إيجاز ها بالآتي:

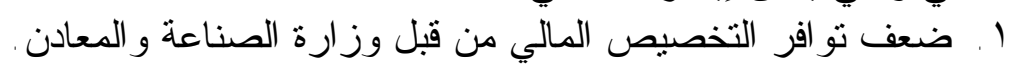

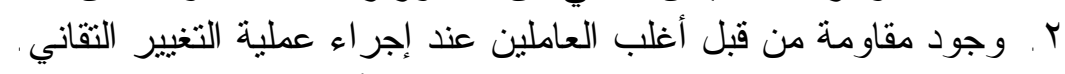

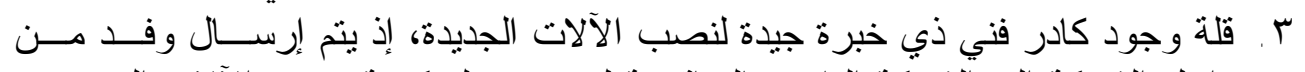

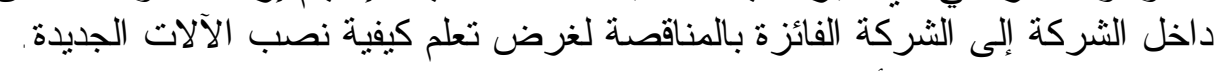
ع. ـ عدم استقر ار الوضع الأمني داخل البلد. 
الصواف وزكريا[ابا]

الإستتناجات و المقترحات

أولاً - الإستتناجات واتهات

1 ـ وجه الكثثر من الباحثين النظر إلى أهمية دراسة التغييرات التقانية بوصفها الأســاس

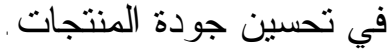
r ـ اتفاق معظم الباحثين على أن التطور ات التقانية من أهم الدوافع التــي تــدفع باتجـــاه التغيير التقاني. r. سعي المنظمة المبحوثة للحصول على الدعم من قبل وز ارة الصناعة و المعادن لتوفير التقانة الحديثة. ـ ـ التخصيص المالي وتحسين جودة المنتجات يعد من أهم الدو افع التــي تـدفع باتجـــاه التغيير التقاني داخل المنظمة المبحوثة. ๑. عندما يحدث التغيير التقاني داخل المنظمة المبحوثة بتم بأسلوب النقلة السريعة.

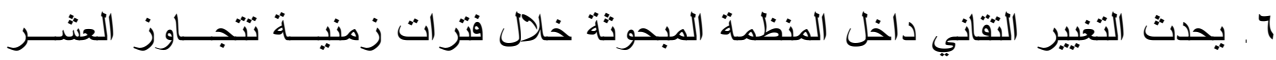
سنو ات.

ثانياً - المقترحات

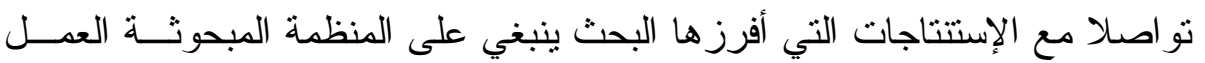

( ب تحديد فتر ات زمنية ثانية لتقيم التقانة الحالية ويفضل كل (خمس سنو ات)

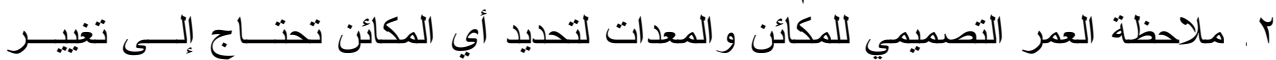

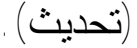

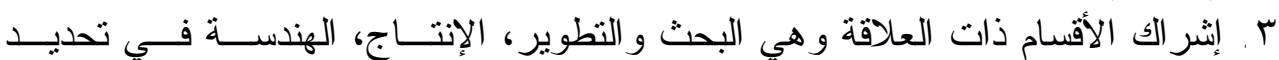

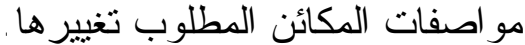

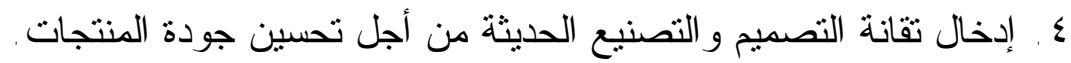

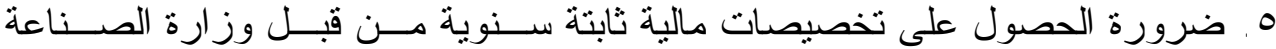
و المعادن لإجر اء التغيير ات التقانية. 7 ـ أررورة إقامة البر امج التدريبية لتدريب الأفر اد العاملين على مو اكبة التقانة الحديثة.

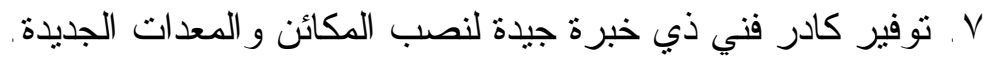

\section{أولاً - المر اجع باللغة العربية}

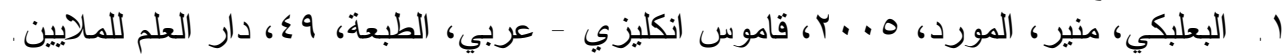

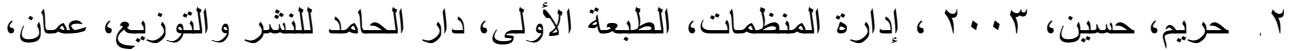

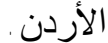
r. داغر ، منقذ محمد، وصالح، عادل حرحوش، . . . r، نظرية المنظمة و السلوك التظظيمي، دار

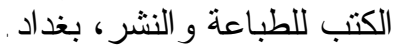

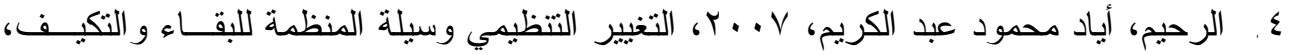

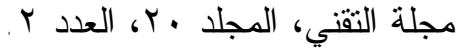




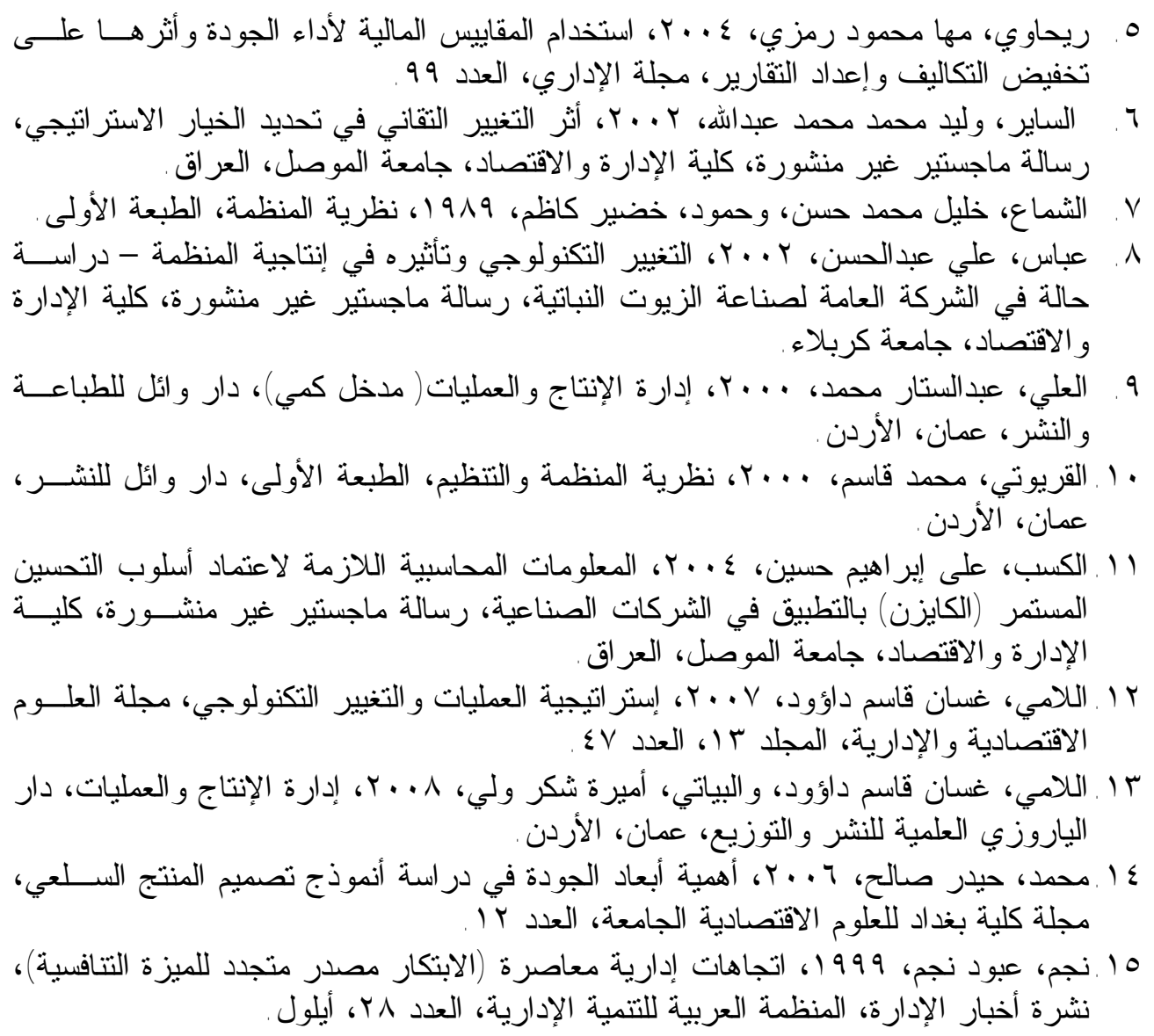

\section{ثانياً - المراجع باللغة الاجنبية}

1. Bergman, Bo and Klefsio, Benget, 1994, Quality, McGraw-Hill Co., Sweden.

2. Chase, Richard B. and Aquilano, Nicholas J., 1995, Production and Operation Management, $7^{\text {th }}$ ed., McGraw-Hill, Inc., USA.

3. Crosby, P. B. and Ivancevich, J. M., 1997, Management: Quality and Competitiveness, $2^{\text {nd }}$ ed., McGraw-Hill Co..

4. Daft, Richard L, 2003, Management, $6^{\text {th }}$ ed., South-Western, Inc., USA.

5. Davis, Mark M. and Aquilano, Nicholas J., and Chase, Richard B., 2003, Fundamentals of Operations Management, $4^{\text {th }}$ ed., McGraw-Hill, USA.

6. Dessler, Gary, 1998, Management, $1^{\text {st }}$ ed., Prentice-Hall, USA.

7. Dilworth, James B., 1996, Operations Management, $2^{\text {nd }}$ ed., McGraw-Hill, Inc., USA.

8. Evans, James R., 1997, Production / Operation Management: Quality, Performance and Value, $5^{\text {th }}$ ed., West Publishing Co., USA.

9. Evans, James R., and Collier, David A., 2007, Operations Management, SouthWestern, USA.

10. Goetsch, David L., and Davis, Stanley B., 1997, Introduction to Total Quality, $2^{\text {nd }}$ ed., McGraw- Hill Co., USA.

11. Griffin, Ricky W., 2002, Management, $7^{\text {th }}$ ed., Houghton Mifflin Co., USA 


\section{الصواف وزكريا[rri}

12. Heizer, Jay, and Render, Barry, 1999, Principles of Operations Management, $3^{\text {rd }}$ ed., Prentice Hall, Inc., USA.

13. Hellriegel, Don, Slocun Jr., John W. and Woodman, Richard W., 2000, Organizational Behavior, $6^{\text {th }}$ ed., South Western, USA.

14. Hodge, B. J. and Anthony, William P., 1991, Organization Theory, $4^{\text {th }}$ ed., Allyn and Bacon, Inc., USA.

15. Kaplan, Roberta S. and Tkinson, Anthony A., 1998, Advanced Management Accounting, $3^{\text {rd }}$ ed., Prentice Hall, Inc., USA.

16. Krajewski, lee J., and Ritzman, Larry P., 2005, Operations Management, $7^{\text {th }}$ ed., Pearson Education, USA.

17. Noori, Hamid and Radford, Russell, 1995, Production and Operations Management, McGraw-Hill Co., USA.

18. Robbins, Stephen P., and Decenzo, David A., 2001, Fundamentals of Management, $3^{\text {rd }}$ ed., Pearson education Asia, India.

19. Russell, Roberta, S. and Taylor, Barnard, W., 1998, Operations Management, $2^{\text {nd }}$ ed., Prentice Hall, Inc., USA.

20. Schermerhorn, John R., and Hunt, James G., and Osborn, Richard N., 2003, Organizational Behavior, $7^{\text {th }}$ ed., John Wiley and Sons, Inc., USA.

21. Slack, Nigel, and Chambers, Stnart, and Harlana, Christine, and Harrison, Alan, and Johnston, Robert, 1998, Operations Management, $2^{\text {nd }}$ ed., Prentice Hall, Inc., Britain.

22. Slack, Nigel; Chambers, Stnart, and Johnston, Robert, 2004, Operations Management, $4^{\text {th }}$ ed., Prentice Hall, Inc., Madrid, Spain.

23. Stevenson, William J., 1999, Production / Operation Management, $6^{\text {th }}$ ed., McGrawHill, Co., USA.

24. Wright, Patrick M., and Noe, Raymond A., 1996, Management of Organization, McGraw-Hill., USA. 